\title{
The Factors That Influence the Integration of Chinese Cross-Border M\&A
}

\author{
Pan $\mathrm{Yu}^{*}$ \\ School of management, Shanghai University, Shanghai, China. \\ *18394025838@163.com
}

Keywords: Cross-border M\&A; integration; strategy tripod framework.

\begin{abstract}
In this paper, we study the factors that influence the integration of Chinese cross-border M\&A from three perspectives: Resource-Based View, Industry-Based View \& Institution-Based View. We use logistic regression to carry out hypothesis testing, the main conclusions are as follows: High-tech Industries M\&A, Product Complementarity and Cultural Distance are significantly negatively related to the integration of Chinese cross-border M\&A. Market Complementary, Value Chain Complementary, Overseas Experience and State-owned Enterprises are positively related to the integration. There is no significant relationship between the quality of host country institution and integration of Chinese.
\end{abstract}

\section{Introduction}

Chinese companies are actively participating in the internationalization process through overseas M\&A (Ma Inching et al., 2014; TianHaifeng et al., 2015). As a key step in the realization of value in overseas M\&A, M\&A integration has also received great attention from scholars. Reviewing existing studies, Chen et al. (2015), Sameer et al. (2013), and Purina et al. (2006), based on resource-based theories, studied the effects of resource similarity and complementarity on overseas M\&A integration and M\&A performance. In order to understand the integration decision-making behavior of Chinese companies' overseas mergers and acquisitions in a more comprehensive and clear manner, this paper will use PengWeigang's strategic three-pillar theory as the basis to conduct in-depth analysis of the influencing factors of Chinese companies' overseas mergers and acquisitions from the three levels of industry, resources, and systems.

\section{Literature Review and Hypothesis}

The Resource-Based View argues that the company's internationalization behavior is a function of resource differences between companies. The Industry-Based View argues that the structural characteristics of the industry will affect the behavior of the company. Although the competition structure of different industries is not the same, the decisions made by companies are to form their own unique competitive advantages. The resource-based and industrial-based views are based on the internationalization theory developed by western developed countries. With the continuous deepening of the internationalization of Chinese companies and the improvement of our understanding of the internationalization of enterprises, the study of the system becomes more and more important.

This article will make a comprehensive analysis of the influencing factors of Chinese companies' overseas M\&A integration decisions from the following three perspectives based on the three pillars of strategy: industry, resources, and institutions.

\subsection{Impact of Industry Factors on M\&A Integration Decisions.}

In general, post-merger integration is needed to improve the productivity of the company (Shimizu et al., 2004), but we believe the high-tech industry is special. Integration will be accompanied by the loss of autonomy, and the loss of autonomy will be detrimental to the company's own innovation performance (Very et al., 1997). In summary, we assume that: 
H1: For overseas acquisitions of high-tech industries, Chinese M\&A parties tend to be unconformable.

\subsection{Impact of Resource Factors on M\&A Integration Decisions.}

\subsubsection{Product Complementation.}

Product complementarity is considered to be one of the important sources of merger and acquisition synergy. The complementary potential of product synergy comes from product line expansion and extension. By effectively combining the complementary production resources of both parties and reducing production costs, the integration will generate value in economies of scale (Purina et al., 2006; Shimizu et al., 2004).In summary, we assume that:

$\mathrm{H} 2$ : Under the condition that the products of both parties are complementary to each other, Chinese M\&A parties are more inclined to integrate.

\subsubsection{Value Chain Complementarity.}

Porter believes that various links between value chains can be an important source of synergies, and that enterprises' competitive advantages really come from the optimization of value chains. Under the condition of complementary value chain, two separate links in a value chain will be integrated into the same company, creating opportunities for the synergy effect in the value chain. In summary, we assume that:

H3: Under the condition that the value chain of M\&A parties is complementary, Chinese M\&A parties tend to integrate.

\subsection{Impact of Institutional Factors on Merger and Acquisition Integration Decisions. 2.3.1 Host Country Institutional Environment.}

Based on transaction cost theory, effective government supervision, high levels of legality, and strong control of corruption in the host country can help reduce the risk and uncertainty of mergers and acquisitions activities in the host country, reduce transaction costs, and generate positive feedback on performance. In summary, we assume that:

H4: The better the host country institutional environment, the more inclined the Chinese M\&A parties to integrate.

\subsubsection{Merger Party Ownership.}

For the sake of resource security and the introduction of advanced technology, the integration of state-owned enterprises after overseas mergers and acquisitions is necessary. Relatively speaking, private enterprises receive much less direct pressure from the government. Therefore, we assume:

H5: In overseas mergers and acquisitions, state-owned enterprises are more inclined to integrate.

\section{Methods and Data}

The data in this article is from Database and the Wind database. The selected sample is the successful case of overseas mergers and acquisitions by Chinese companies in 2003-2016, totaling 1107 cases. The main sources of micro-level data required for research are the credibility of the overseas acquisition database and the Global Economic Freedom Index. After excluding samples with incomplete information, the paper finally selected 221 full-fledged case samples for research.

\subsection{Variables.}

Dependent variable: Integration. If mergers and acquisitions are involved in the regular operations of the target company, the business system of the target company, including R\&D, marketing, aftersales service, branding, etc., is organically integrated into its own business operation system. The integrated parameter is set to 1 . If the target company still maintains the independence and autonomy of the business after being acquired, it is deemed to be unconformity and the variable is taken as 0 .

\subsection{Independent Variable.}

Product Complementarity: We believe that product complementarity comes from product line expansion and extension. Product complementation is a dummy variable, if the product is complementary, Prod $=1$, otherwise $=0$.

Value chain complementation: Dummy variable, if the two sides of the merger have an upstream and downstream relationship in the value chain, then it is set to 1 , otherwise $=0$. 
High-tech industry: According to the "Management Measures for High-tech Enterprises," this article defines high-tech enterprises at the national and provincial levels as high-tech enterprises. We introduced dummy variables. If the company is a high-tech company, Techno $=1$ otherwise Techno $=0$.

Ownership: If the company is state-owned, $\mathrm{SOE}=1$, otherwise $\mathrm{SOE}=0$.

Host country institutional environment: Measuring the institutional environment of the host country according to the Index of Investment Freedom. Among them, 0 means no investment, and 100 means that the country's investment is completely free.

\subsection{Control Variable.}

Cooperation basis: If the merger between the two parties has had business cooperation before, Coop $=1$, otherwise $=0$.

Cross-sector acquisitions: If cross-industry mergers and acquisitions, Cross $=1$, otherwise $=0$.

\subsection{Estimation Method.}

Since the dependent variable studied in this paper is a dichotomous variable, it is statistically significant as a matter of probability. Therefore, it is reasonable to test using the maximum likelihood function. We use the binary logistic model to estimate the parameters. The formula is as follows:

$$
\operatorname{In}\left(\frac{\mathrm{p}}{1-\mathrm{p}}\right)=\beta 0+\beta 1 \times 1+\beta 2 \times 2 \ldots \ldots+\mu
$$

Among them, P represents the probability of integration after merger and acquisition, Xi represents the independent variable, including all the independent variables included in the model, and $\beta$ if represents the regression coefficient corresponding to each variable. This study will use SPSS 22.0 maximum likelihood estimation method to determine the regression coefficient.

\section{Results and Discussion}

\subsection{Regression Analysis.}

We performed a correlation test on the model. All correlation coefficients were less than 0.7 . We also used the Tolerance and Variance Inflation Factors (VIF) to perform linearity tests on all variables. The results show that there is no multicollinearity.

The chi-square value of model 1 is 83.54 , which is significant at the $1 \%$ level, indicating that the significance of the model passed the test and the overall degree of fit is better. From the test results, the high-tech industry is negatively related to the integration decision. Assume that $\mathrm{H} 1$ is verified.

\subsection{Robustness Test.}

This article also uses the binary variable dependent Legit model for robustness detection, and in order to eliminate the error impact of statistical bias, we will make the following adjustments to the variable parameters: 1) In studying the impact of the state-owned property, we used the previous method (Cui \& Jiang, 2012) to replace the ownership of the cumulative state-owned shares of the top ten non-tradable shareholders.2) Although they belong to overseas M\&As, the acquisition of the M\&A target in Hong Kong or Taiwan may significantly increase the willingness of Chinese M\&A parties to integrate. After identification, a total of 13 cases were mergers and acquisitions that occurred in Hong Kong or Taiwan. This article will remove the 13 cases from the sample and return to test stability.3) Overseas experience is replaced by the investment experience of the host country. The robustness test regression results showed that the results remained stable (Model 5). In summary, previous research findings have all been tested in stability tests.

Model 2 examines the impact of resource layer factors on integration decisions. We find that product complementation has a significant impact on Chinese companies' overseas merger and acquisition integration decisions $(1 \%$ level), but the correlation coefficient between the two is negative (-1.455). We believe that the possible explanation of this result is based on the concentric diversification of core technologies. So, $\mathrm{H} 2$ is not verified. However, the value chain complementarity and integration decision are positively related, $\mathrm{H} 3$ is verified.

In Model 3, the coefficients of all the system variables are in line with expectations and are all significant at the $1 \%$ level, $\mathrm{H} 4$ passes the test. $\mathrm{H} 5$ does not pass the test. 
Model 4 lists the results of regression of all variables, and it can be found that the regression results maintain stability with the previous regression.

Table 1. Model Binary Logistic Regression Results

\begin{tabular}{|c|c|c|c|c|c|c|c|c|c|c|}
\hline & \multicolumn{2}{|c|}{ Model1 } & \multicolumn{2}{|l|}{ Model2 } & \multicolumn{2}{|c|}{ Model3 } & \multicolumn{2}{|c|}{ Model4 } & \multicolumn{2}{|c|}{ Model5 } \\
\hline & Coefficient & $\begin{array}{c}\text { Standard } \\
\text { error }\end{array}$ & Coefficient & $\begin{array}{l}\text { Standard } \\
\text { error }\end{array}$ & Coefficient & $\begin{array}{c}\text { Standard } \\
\text { error }\end{array}$ & Coefficient & $\begin{array}{c}\text { Standard } \\
\text { error }\end{array}$ & Coefficient & $\begin{array}{c}\begin{array}{c}\text { Standard } \\
\text { error }\end{array} \\
\end{array}$ \\
\hline $\begin{array}{c}\text { High tech } \\
\text { industry }\end{array}$ & $-1.027 * *$ & 0.491 & & & & & $-1.460^{*}$ & 0.819 & $-1.833 * *$ & 0.867 \\
\hline $\begin{array}{c}\text { Complementary } \\
\text { products }\end{array}$ & & & $-1.455^{* * *}$ & 0.568 & & & $-1.736 * *$ & 0.685 & $-1.659 * *$ & 0.748 \\
\hline $\begin{array}{c}\text { Value chain } \\
\text { complementarity }\end{array}$ & & & $1.737 * * *$ & 0.448 & & & $2.154 * * *$ & 0.54 & $2.374 * * *$ & 0.578 \\
\hline Ownership & & & & & $1.304 * * *$ & 0.496 & $1.196^{*}$ & 0.712 & & \\
\hline $\begin{array}{c}\text { (State-owned } \\
\text { equity ratio) }\end{array}$ & & & & & & & & & $.025^{*}$ & 0.015 \\
\hline $\begin{array}{l}\text { Host country } \\
\text { institutional } \\
\text { environment }\end{array}$ & & & & & 0.016 & 0.025 & 0 & 0.03 & 0.037 & 0.038 \\
\hline $\begin{array}{c}\text { Basis for } \\
\text { cooperation }\end{array}$ & $1.212^{* *}$ & 0.611 & $1.439^{* *}$ & 0.714 & $1.362 * *$ & 0.673 & $1.525^{*}$ & 0.837 & $1.660^{*}$ & 0.959 \\
\hline $\begin{array}{l}\text { Cross-industry } \\
\text { mergers and } \\
\text { acquisitions }\end{array}$ & $-2.530 * *$ & 1.028 & $-3.453 * * *$ & 1.294 & $-3.312 * * *$ & 1.159 & $-3.896 * * *$ & 1.467 & $-4.088^{* * *}$ & 1.55 \\
\hline Constant & $-1.155^{* *}$ & 0.512 & $-2.586 * * *$ & 0.724 & -2.293 & 1.933 & -0.655 & 2.75 & -2.388 & 3.034 \\
\hline -2Log likelihood & 180.63 & 158.11 & 166.26 & 135.91 & 120.56 & & & & & \\
\hline chi-square test & $83.54 * * *$ & & $106.063 * * *$ & & & $2 * * *$ & 124 & $66 * * *$ & 123. & $62 * * *$ \\
\hline$(\mathrm{N})$ & 221 & & 221 & & 21 & & 2 & & 20 & \\
\hline
\end{tabular}

Note: Dependent variable: Integration decision

$*$ : be significant at the 0.1 level

$* *$ : be significant at the 0.5 level

$* * *$ : be significant at the 0.01 level

\section{Conclusions}

The findings of this article are as follows

(1) Chinese enterprises are more willing to give auto-purchased companies sufficient autonomy over high-tech attributes. The integration of high-tech industries will involve complex knowledge flows, which puts higher requirements on the knowledge and management capabilities of M\&A companies. However, Chinese M\&A parties do not have the ability to integrate knowledge based on knowledge.

(2) We believe that in overseas M\&A, Chinese companies are relatively weak in terms of technology and management capabilities, and product-based integration has high requirements on the controlling power of M\&A parties, which results in the lack of ability for Chinese M\&A parties to integrate products. Integration is often not feasible.

(3) Complementing the value chain will significantly increase the possibility of Chinese enterprise integration.

(4) There is a very strong force behind the internationalization of Chinese companies, namely the Chinese government. Ownership is the most direct and effective way for the Chinese government to guide corporate behavior. Compared with private enterprises, state-owned enterprises are more likely to integrate because state-owned enterprises are larger and more powerful. For the implementation of post-merger integration, state-owned enterprises have the ability to obtain synergies from integration.

(5) The quality of the host country's institutional environment is not related to the integration of Chinese companies. It shows that M\&A integration is also a process of internal resource readjustment. The host country's institutional environment will affect the effectiveness of Chinese companies' access to resources from the external environment, but it will not have a significant impact on the efficiency of internal resource integration. 


\section{References}

[1]. Ma Inching, Jiao Guan Nan, Ma Mangy. Dynamic Changes and Driving Factors of Chinese Enterprises' Overseas M\&A Industry Distribution: 2005-2012 [J]. Macroeconomic Research, 2014(1): 33-43.

[2]. Sheer a, Castanet X, Souder D. Synergy sources, target autonomy, and integration in acquisitions [J]. Journal of Management, 2013, 39(3): 604-632.

[3]. Parana P, Singh H, and Zolfo M. Organizing for innovation: Managing the coordinationautonomy dilemma in technology acquisitions [J]. Academy of Management Journal, 2006, 49 (2): 263- 280.

[4]. Chen Feeing, Chen Halo, Li Fee. The Similarity, Complementarity, and Innovation Performance of Resource-Based Overseas M\&A: The Mediating Role of Integration and Target Autonomy [J]. International Trade Issues, 2015(7):137-147.

[5]. Cui L, Jiang F. State ownership effect on firms' FDI ownership decisions under institutional pressure: a study of Chinese outward-investing firms [J]. Journal of International Business Studies, 2012, 43(3): 264-284. 